\title{
Sintering Preparation of 15 wt\% Cr Cast Iron as well as Its Mechanical Properties and Impact Abrasive Wear
}

\author{
Liyang Xiao1, Pingan Xiao1*, Liviu Brândușan², Jinghong Gu¹, Zhongtao Li', Simin Gu \\ ${ }^{1}$ College of Materials Science and Engineering, Hunan University, Yuelu District, 410082 Changsha, 2 Lushan Road (S), China \\ 2 Department of Materials Science and Engineering, Faculty of Materials and Environmental Engineering, Technical University of \\ Cluj-Napoca, 400641 Cluj-Napoca, 103-105 Muncii Avenue, Romania \\ * Corresponding author, e-mail: changcluj@163.com
}

Received: 25 February 2020, Accepted: 11 May 2020, Published online: 21 October 2020

\begin{abstract}
15 wt\% Cr sintered High Chromium Cast Iron ( $\mathrm{HCCl}$ ) with full density was successfully prepared by Super-solidus Liquid Phase Sintering (SPLS) technique, with water atomized $15 \mathrm{wt} \% \mathrm{Cr}$ high chromium cast iron powder as initial materials. Its densification behavior and microstructure evolution in SPLS process and mechanical properties were investigated systematically. Additionally, the impact abrasive wear resistance under different impact energies were also analyzed and compared with another sintered $\mathrm{HCCl}$ with 20 wt $\% \mathrm{Cr}$. The results indicated that sintering temperature has a strong influence on the sintered alloy's density, hardness, impact toughness and bending strength. The M7C3 type ( $\mathrm{M}$ is $\mathrm{Cr}$ and Fe) carbides were obviously coarsened as temperature increased and their rodshaped branches were fully developed at the same time, thereby resulting in carbide network formation in the matrix. The reasonable sintering temperature range was $1195-1205^{\circ} \mathrm{C}$, and the optimum mechanical properties had the hardness of $63.9 \mathrm{HRC}$, bending strength of $2112.65 \mathrm{MPa}$ and impact toughness of $7.92 \mathrm{~J} / \mathrm{cm}^{2}$. What is more important impact abrasive wear test results indicated $15 \mathrm{wt} \% \mathrm{Cr}$ sintered $\mathrm{HCCl}^{\prime}$ s wear resistance could be comparable to $20 \mathrm{wt} \% \mathrm{Cr}$ sintered $\mathrm{HCCl}$ under impact energy $1 \sim 3 \mathrm{~J} / \mathrm{cm}^{2}$, and it is more cost effective.
\end{abstract}

Keywords

High Chromium Cast Iron ( $\mathrm{HCCl}$ ), sintering, microstructure evolution, mechanical property, impact abrasive wear

\section{Introduction}

High Chromium Cast Iron (HCCI) has been widely used in mining and cement industries because of its excellent wear resistance [1]. The focus of research is reducing material wear rate [2]. Some techniques have been adopted to further enhance HCCI's mechanical properties and expand its application range, such as alloying [3-13], modification treatment [14, 15] and heat treatment [3, 16-21]. These techniques can strengthen HCCI's matrix, optimize its microstructure, and adjust $\mathrm{M}_{7} \mathrm{C}_{3}$ type carbide's size and morphology. Nowadays, cast HCCI's mechanical performance has the bending strength of $1000 \sim 1200 \mathrm{MPa}$, hardness of 58 62 HRC and impact toughness of around $6 \sim 8 \mathrm{~J} / \mathrm{cm}^{2}$ with a $10 \times 10 \times 50 \mathrm{~mm}$ unnotched sample. However, its performance is usually disqualified in applications with high impact due to its insufficient strength and impact toughness.

In a recent report [22], a sintered HCCI with 19.6 wt\% Cr was fabricated by a Super-solidus Liquid
Phase Sintering (SLPS) technique [23]. Its main mechanical properties except hardness were doubled because of its unique microstructure evolved in SLPS process, so it is highly possible that sintered HCCI would become a good wear resistance alloy candidate for impact abrasion wear application. However, the preparation cost of sintered HCCI is certainly much higher than that of cast one. Therefore, the research is needed to make the preparation more cost-effective.

In this paper, the sintered preparation of HCCI with $15 \mathrm{wt} \% \mathrm{Cr}$ was systematically investigated, aiming at reducing initial powders' cost by reducing chromium addition in HCCI. Its densification behavior, microstructure evolution, phase composition and mechanical property were mainly analyzed and compared. In order to evaluate the cost performance, the impact abrasion resistance of sintered HCCI with $15 \mathrm{wt} \% \mathrm{Cr}$ and $20 \mathrm{wt} \% \mathrm{Cr}$ was evaluated separately, and the wear mechanism was also discussed. 


\section{Experimental methods}

\subsection{Preparations of samples}

Two kinds of hypoeutectic HCCI initial powders with $15 \mathrm{wt} \% \mathrm{Cr}$ and $20 \mathrm{wt} \% \mathrm{Cr}$ are water atomized and the results of their composition analysis are listed in Table 1. The initial powder morphology of $15 \mathrm{Cr}$ hypoeutectic HCCI initial powder is shown in Fig. 1, which also presents the microstructure of powder by a scanning electron microscope. As shown in Fig. 1, the powders are of irregular droplets and there are many fine and dendritic carbides in the microstructure. The size distribution of the powders is measured by Mastersizer 3000 laser particle size analyzer and the median diameter (D50) was about $24.7 \mu \mathrm{m}$.

The initial powders were firstly added with a mass fraction of $1 \mathrm{wt} \%$ of styrene-butadiene rubber to improve their pressability. Then, the mixed initial powders were pressed in a steel mold to produce green samples on a SFLS single-column hydraulic press, with pressing pressure around 200 300 MPa.

SLPS is an effective sintering technique, which is especially suitable for prealloyed powder compact's densification, as the alloy has a wide solidification temperature range $[23,24]$. HCCI has also a wide liquid-solid coexisting region in its phase diagram, and its molten liquid is of vitally low viscosity, which makes it easier for the molten liquid to fill the gaps between powders in the green

Table 1 Chemical composition of HCCI initial powders (wt.\%)

\begin{tabular}{lccccc}
\hline $\begin{array}{l}\text { HCCI } \\
\text { Code }\end{array}$ & C & Cr & Mo & Si & Fe \\
\hline $15 \mathrm{Cr}$ & 3.00 & 15.00 & 1.35 & 1.12 & Bal. \\
$20 \mathrm{Cr}$ & 2.72 & 19.68 & 1.43 & 1.05 & Bal. \\
\hline
\end{tabular}

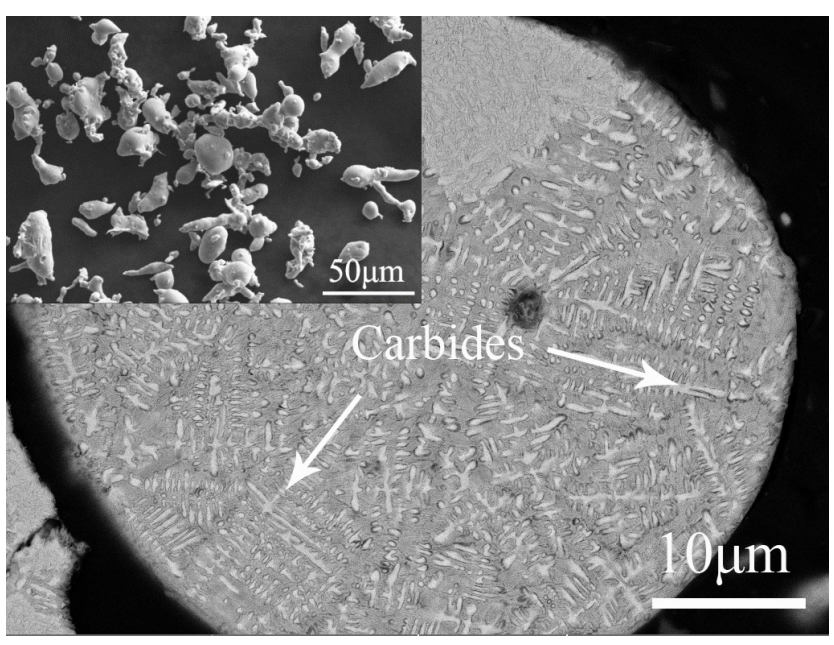

Fig. 1 The morphology and microstructure of water atomized $15 \mathrm{Cr}$ hypoeutectic HCCI powders. compact. Therefore, SLPS was used in this research. $15 \mathrm{Cr}$ HCCI powder was tested on a STA449C differential thermal analyzer to fix its solidification temperature range and the result indicated it is of $1191{ }^{\circ} \mathrm{C}-1238{ }^{\circ} \mathrm{C}$. So, in order to evaluate the influence of temperature on the alloy's densification, microstructure evolution and mechanical properties, the sintering temperature was gradually increased at the range of $1191{ }^{\circ} \mathrm{C}-1238{ }^{\circ} \mathrm{C}$. then, the convenience sintering time was kept at 90 minutes in this research.

The green compact was sintered by SLPS technique in a GSL1600X tube furnace with a vacuum about 5 to $20 \mathrm{~Pa}$. The green compact was firstly heated to $250{ }^{\circ} \mathrm{C}$ and held for $30 \mathrm{~min}$ to remove residual water vapor in it, and then heated to $470{ }^{\circ} \mathrm{C}$ and held for $30 \mathrm{~min}$ to remove the molding agent, and further heated to $1000^{\circ} \mathrm{C}$ at the rate of $4{ }^{\circ} \mathrm{C} / \mathrm{min}$. Afterwards, the compact was heated to sintering temperature $\left(1185^{\circ} \mathrm{C}, 1190{ }^{\circ} \mathrm{C}, 1195^{\circ} \mathrm{C}, 1200^{\circ} \mathrm{C}, 1205^{\circ} \mathrm{C}\right)$ at a heating rate of $2{ }^{\circ} \mathrm{C} / \mathrm{min}$ and held for $90 \mathrm{~min}$. Finally, the samples were cooled to $450{ }^{\circ} \mathrm{C}$, at rate of $4{ }^{\circ} \mathrm{C} / \mathrm{min}$, then furnace cooled to room temperature.

In order to get the theoretical density, the high chromium cast iron sample, obtained by melting the same initial powder, is measured and used as the theoretical density.

\subsection{Characterization of sintered HCCI}

The density of sintered/casted HCCI samples was measured by the Archimedes method and their phase composition was analyzed with a MiniFlex type X-ray diffractometer (XRD, $\mathrm{Cu}$ target, $\lambda=0.15405 \mathrm{~nm}$ ). Microstructure inspection was operated on a Leitz-MM6 Optical Microscopy (OM) and/or a FEI QUANTA 200 environmental Scanning Electron Microscope (SEM).

In order to observe the three-dimensional morphology of carbides in a sintered alloy, a sample was firstly electrolyzed in a perchloric acid alcohol solution for more than 24 hours to dissolve its metal matrix, and then the solution was filtered to gather carbides. The obtained carbides were washed with water and later separated in a high-speed centrifuge.

In order to determine the volume fraction of carbides in a sintered sample's microstructure, analysis software of Image-Pro Plus was employed to analyze statistically its microstructure pictures obtained by OM. The area fraction of a phase in a picture is equivalent to its volume percentage according to stereological principles. The final area percentage of carbides takes the average of statistical analysis results from more than 10 different optical micrographs $(200 \times)$ for each sample. 
The evaluated mechanical properties of the sintered HCCI include hardness, impact toughness and bending strength. Hardness was detected on a Wilson RB2000 fully automatic Rockwell hardness tester and each result take the average of more than 5 inspections. Bending strength was measured on an Instron 3369 electronic versatile testing machine with a $5 \times 5 \times 35 \mathrm{~mm}$ specimen; Impact toughness was examined on a XJ-40A pendulum impact tester with a unnotched $5 \times 5 \times 55 \mathrm{~mm}$ test piece. The final result of both impact toughness and bending strength takes the average of more than three inspections.

Impact abrasive wear test of the sintered alloy was carried out on an MLD-10 dynamic abrasive wear tester. The schematic diagram and experimental parameters of impact abrasive wear test process are shown in Fig. 2 and Table 2, respectively. A $10 \times 10 \times 30 \mathrm{~mm}$ sintered HCCI test sample was used as the upper sample, and the lower sample was a ring of GCr15 steel with hardness of 62 to $64 \mathrm{HRC}$, rotating at $200 \mathrm{r} / \mathrm{min}$. Brown fused alumina particles of 15 mesh were used as abrasive. Its flow rate was set at $15 \mathrm{~kg} / \mathrm{h}$ and the impact frequency between upper and lower samples was of 200 times/min during whole testing process. The total impact abrasive wear test time for each sintered HCCI sample was $60 \mathrm{~min}$, which is carried out in six steps. To be more specific, after each 10 minutes of

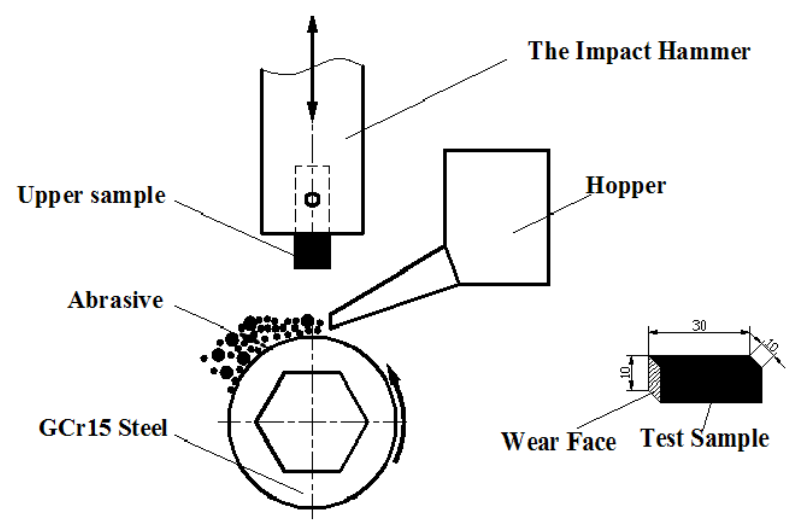

Fig. 2 Schematic diagram of impact abrasive wear test machine and sample

Table 2 Experimental parameters of MLD-10 dynamic abrasive wear tester

\begin{tabular}{lccc}
\hline $\begin{array}{l}\text { Abrasive Flow } \\
\text { Rate }(\mathrm{kg} / \mathrm{h})\end{array}$ & $\begin{array}{l}\text { The Impact } \\
\text { Frequency } \\
(\text { times/min })\end{array}$ & $\begin{array}{c}\text { GCr15 Steel } \\
\text { Rotation Rate } \\
(\mathrm{r} / \mathrm{min})\end{array}$ & $\begin{array}{c}\text { Impact Energy } \\
\left(\mathrm{J} / \mathrm{cm}^{2}\right)\end{array}$ \\
\hline & 200 & 200 & 1 \\
12 & & 2 \\
\hline
\end{tabular}

abrasive impact wear test, the sample is taken out from the test machine and weighed after being ultrasonically cleaned in alcohol solution and then dried. The impact abrasion resistance of a sample was evaluated according to its weight loss before and after the test. The impact energy for the test was set as 1,2 and $3 \mathrm{~J} / \mathrm{cm}^{2}$, respectively, to evaluate the alloy's wear resistance comprehensively. Additionally, the wear surface and subsurface of samples were also inspected by SEM to analyze and discuss their wear behavior and mechanism.

\section{Results and discussion}

\subsection{Densification behavior}

The effect of sintering temperature on density of $15 \mathrm{Cr}$ sintered HCCI is shown in Fig. 3. The result indicates that the density increases slowly as the temperature is increased from $1185^{\circ} \mathrm{C}$ to $1190{ }^{\circ} \mathrm{C}$, and then increases rapidly from $1190{ }^{\circ} \mathrm{C}$ to $1195^{\circ} \mathrm{C}$, and finally reaches a steady peak of around $7.65 \mathrm{~g} / \mathrm{cm}^{3}$ as it is above $1195^{\circ} \mathrm{C}$. In SLPS process, the green compact's densification was closely related to the formation of liquid phase as well as its amount. When the sintering temperature reached the solidus temperature, with the increase of the sintering temperature, liquid phase was formed at first on the surface of powder particles in a green compact. The liquid phase filled the pores between or among them, causing the initial rearrangement. At the same time or later, liquid phase also emerged at grain or sub-grain boundary in the powders, which would break powders into smaller grains, and then secondary grain rearrangement took place. When the temperature was over $1190{ }^{\circ} \mathrm{C}$, there was enough amount

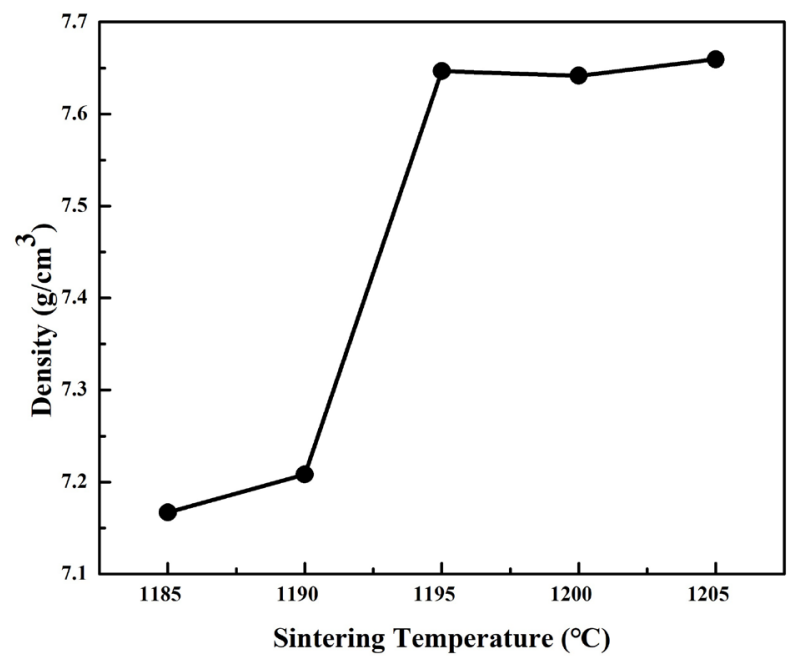

Fig. 3 Effect of sintering temperature on density 
of liquid phase for a compact to process effective densification, hence, its density rose quickly. As the temperature was higher than $1195{ }^{\circ} \mathrm{C}$, the compact had reached full density, and its density was almost unchanged. It was also discovered that when sintering temperature was increased above $1210{ }^{\circ} \mathrm{C}$, compacts began to become deformed because there was excessive amount of liquid phase. Therefore, the optimal sintering temperature range of $15 \mathrm{Cr} \mathrm{HCCI}$ should be $1195^{\circ} \mathrm{C}$ to $1205^{\circ} \mathrm{C}$, so that a sintered body with a full density (with a porosity of less than $1.5 \%$ relative to the theoretical density of $7.74 \mathrm{~g} / \mathrm{cm}^{3}$ ) and an acceptable size and shape can be obtained.
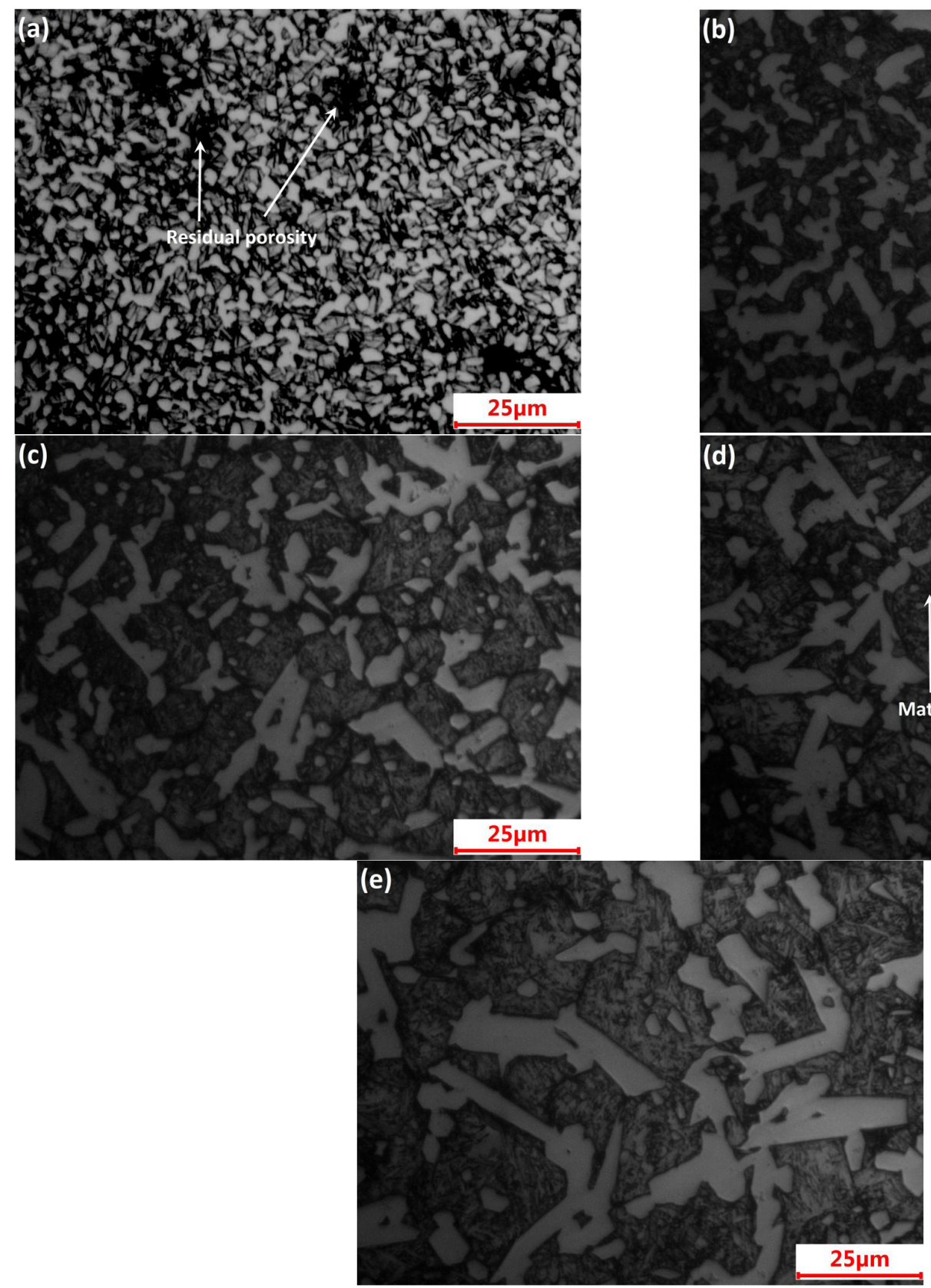

Fig. 4 Effect of sintering temperature on the microstructure evolution: (a) $1185^{\circ} \mathrm{C}$; (b) $1190{ }^{\circ} \mathrm{C}$; (c) $1195{ }^{\circ} \mathrm{C}$; (d) $1200{ }^{\circ} \mathrm{C}$; (e) $1205^{\circ} \mathrm{C}$

\subsection{Microstructure evolution and phase composition}

Fig. 4 illustrates the effect of sintering temperature on the microstructure evolution of $15 \mathrm{Cr}$ sintered HCCI. The microstructure consists of white carbide particles and grey metallic matrix. It can be observed that temperature exerts great influence on carbides' growth and number. The higher the temperature is, the larger the carbide size and the fewer their number become. When sintering was conducted at $1185^{\circ} \mathrm{C}$, there were large number of fine carbides with some black pores in the matrix, indicating low densification of the sample, as can be seen in Fig. 4 (a). As the sintering temperature increased, fine
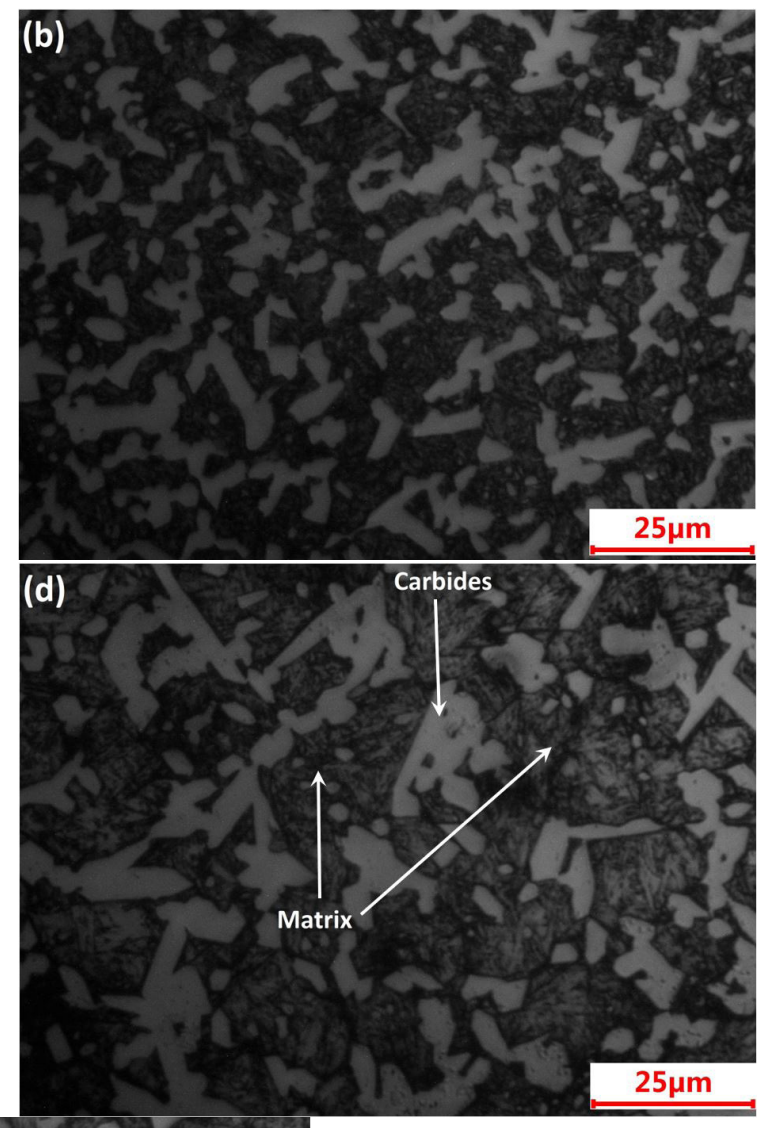

$25 \mu \mathrm{m}$ 
carbides were gradually dissolved, and large carbides became coarser due to Ostwald ripening during SLPS process. At the same time, the cross-linking between large carbides got more serious, which would deteriorate the alloy's strength and toughness.

As shown in Fig. 5, the XRD pattern of $15 \mathrm{Cr}$ sintered $\mathrm{HCCI}$ indicates that the component phases are $\mathrm{M}_{7} \mathrm{C}_{3}$ carbide $(\mathrm{M}=\mathrm{Fe}$ or $\mathrm{Cr})$, martensite and a small amount of austenite. It can be seen from Fig. 4 (d) that there are larger massive carbides in the sample. In addition, there are many fine carbides in the matrix, which are secondary carbides precipitated from the austenite matrix during the cooling process, which has also been seen in other reports $[3,7]$. During the cooling process from the solidus temperature to room temperature, austenite will precipitate secondary carbides in the matrix structure. The matrix, composed of austenite and martensite, is strengthened by secondary carbide, which is conducive to the improvement of strength and toughness of sintered HCCI.

The volume fractions of carbide in $15 \mathrm{Cr}$ sintered HCCI prepared at different sintering temperatures are shown in Fig. 6. It can be found that the fractions are substantially stabilized at about $40 \%$. Sufficient holding time at sintering temperature and subsequent controlled slow cooling rate contribute to full precipitation of carbides. Therefore, sintered HCCI can maintain a high carbide volume fraction.

As shown in Fig. 7, the SEM three-dimensional morphologies of eutectic carbides extracted from $15 \mathrm{Cr}$ alloy prepared at different temperatures by deep etching and centrifugal separation are displayed They grew in cluster with rod-shape branches. As sintering temperature was increased, branches became coarsened, and more and more side branches were developed.

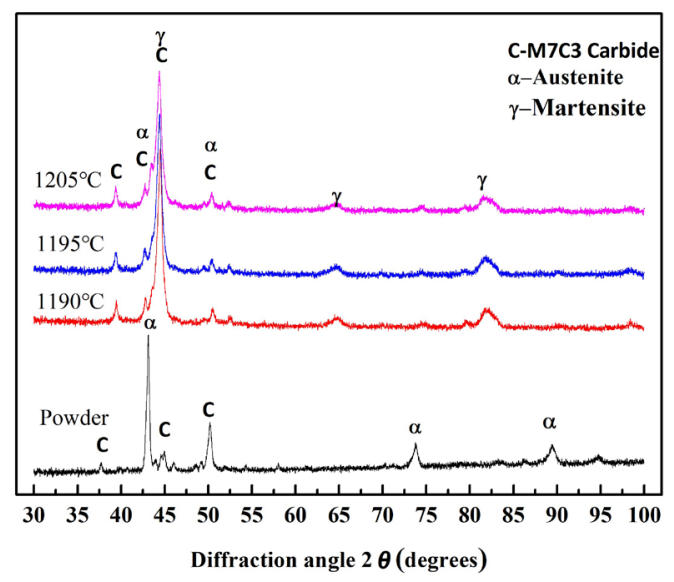

Fig. 5 The XRD patterns of $15 \mathrm{Cr}$ sintered HCCI at different temperature

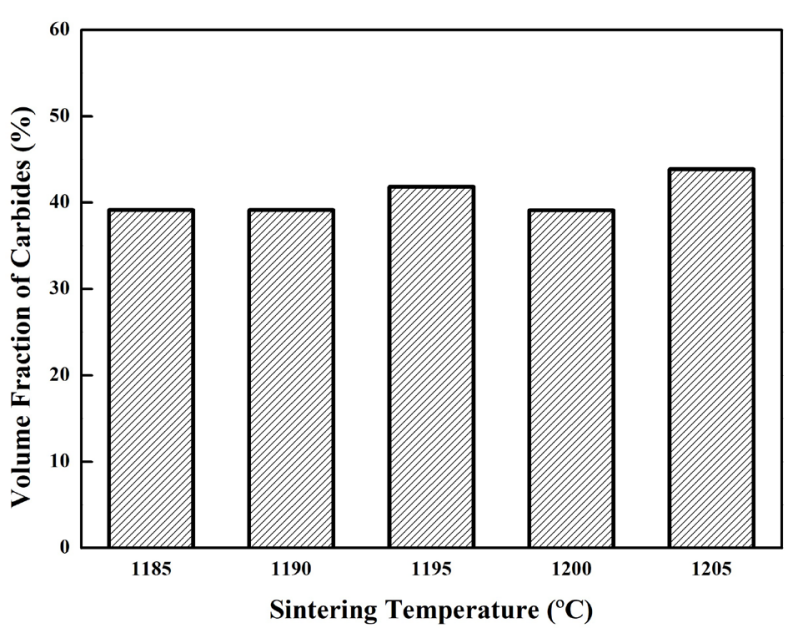

Fig. 6 Effect of sintering temperature on carbide volume fraction of $15 \mathrm{Cr}$ sintered HCCI

When the sintering temperature reached to $1190{ }^{\circ} \mathrm{C}$, primary rod carbides became small and a few short subbranches were developed with needle tip. However, as the sintering temperature reached $1200{ }^{\circ} \mathrm{C}$, primary branches had grown into coarse rods with smooth surface as well as hexagonal cross section, and its side branches had also developed in several ranks, some of which being of a needle tip as shown in Fig. 7 (d). Meanwhile, carbide network was gradually formed in space as their macroscopic rod branches became coarser and coarser as shown in Fig. 7 (e), which was certainly harmful to the alloy's strength and toughness.

\subsection{Mechanical properties}

The relationship between hardness of $15 \mathrm{Cr}$ sintered HCCI and sintering temperature is shown in Fig. 8. As the sintering temperature increased, hardness increased rapidly at first and then remained at about 64 HRC. In comparison with Fig. 3, it could be obviously recognized that there was a close inner relation between hardness and density for sintered $\mathrm{HCCI}$. Both the high $\mathrm{M}_{7} \mathrm{C}_{3}$ carbide volume fraction and amount of martensite in the matrix contributed to $15 \mathrm{Cr}$ sintered HCCI's high hardness.

The influence of sintering temperature on flexural strength and impact toughness of $15 \mathrm{Cr}$ alloy is shown in Fig. 9. Both bending strength and impact toughness rapidly increase initially and then fluctuate and finally decline as sintering temperature increases from $1185^{\circ} \mathrm{C}$ to $1205{ }^{\circ} \mathrm{C}$. Their maximums are reached at $1200{ }^{\circ} \mathrm{C}$, 2112.65 MPa and $7.92 \mathrm{~J} / \mathrm{cm}^{2}$, respectively.

The influence of sintering temperature on flexural strength and impact toughness of $15 \mathrm{Cr}$ alloy is shown in Fig. 9. Both bending strength and impact toughness 

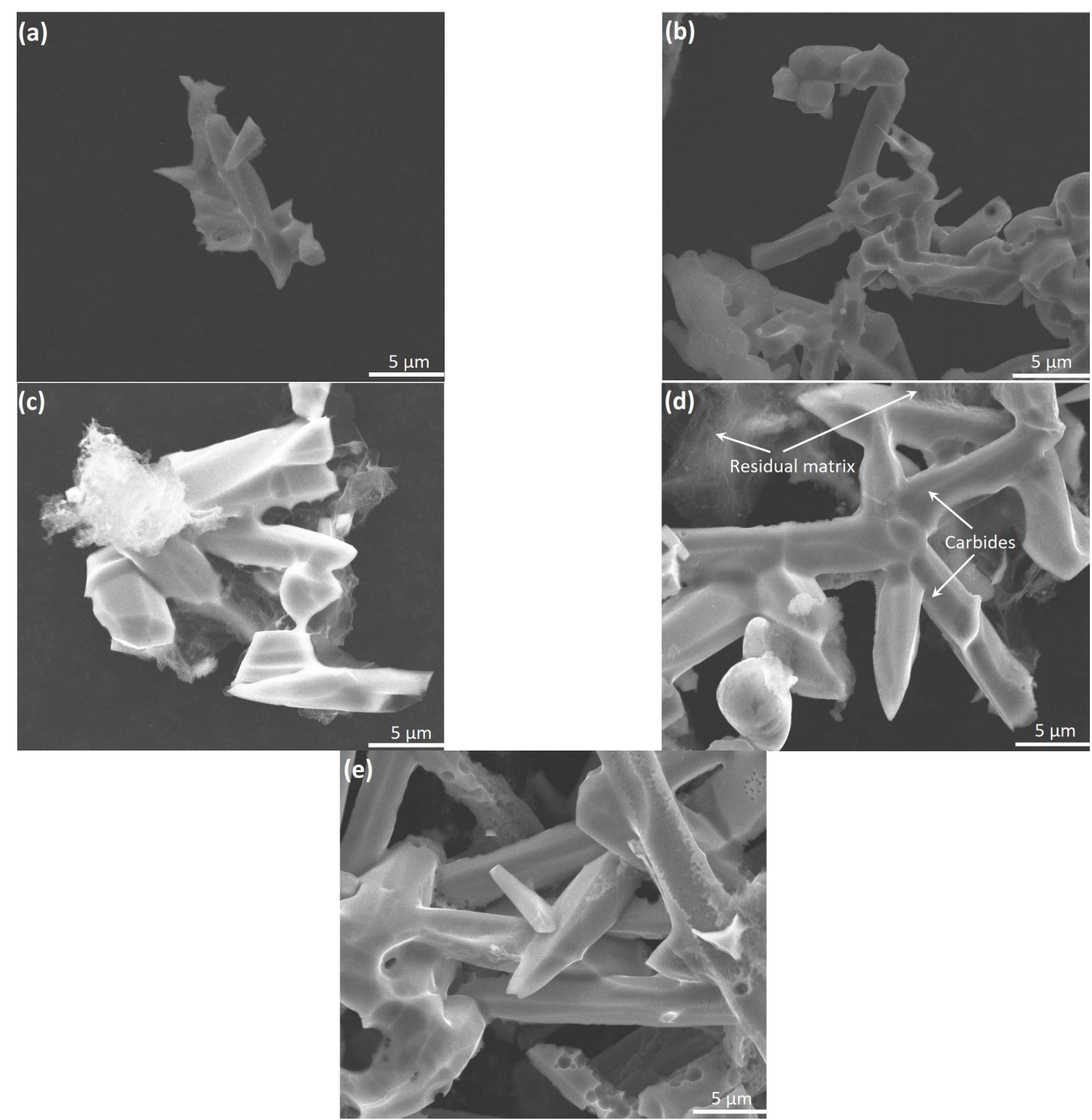

Fig. 7 Three-dimensional morphology of carbides in $15 \mathrm{Cr} \mathrm{HCCI}$ prepared at sintering temperature: (a) $1185^{\circ} \mathrm{C}$; (b) $1190{ }^{\circ} \mathrm{C}$; (c) $1195^{\circ} \mathrm{C}$; (d) $1200{ }^{\circ} \mathrm{C}$; (e) $1205^{\circ} \mathrm{C}$

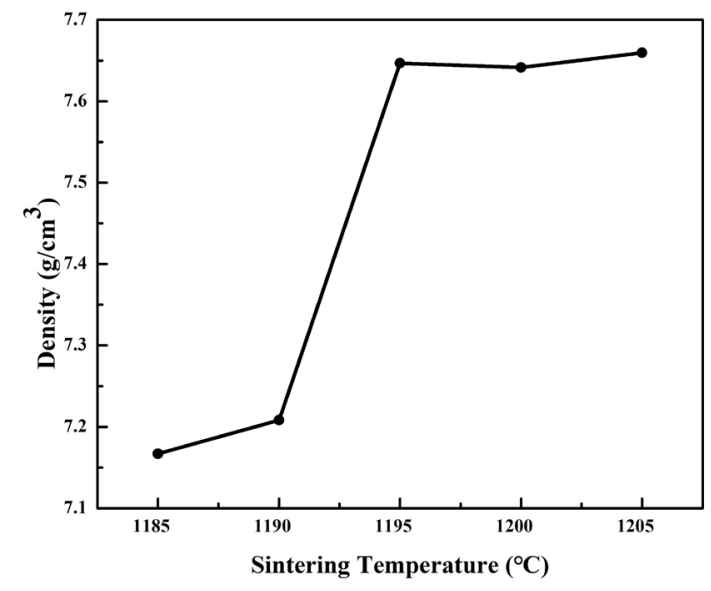

Fig. 8 Effect of sintering temperature on sintered HCCI's hardness

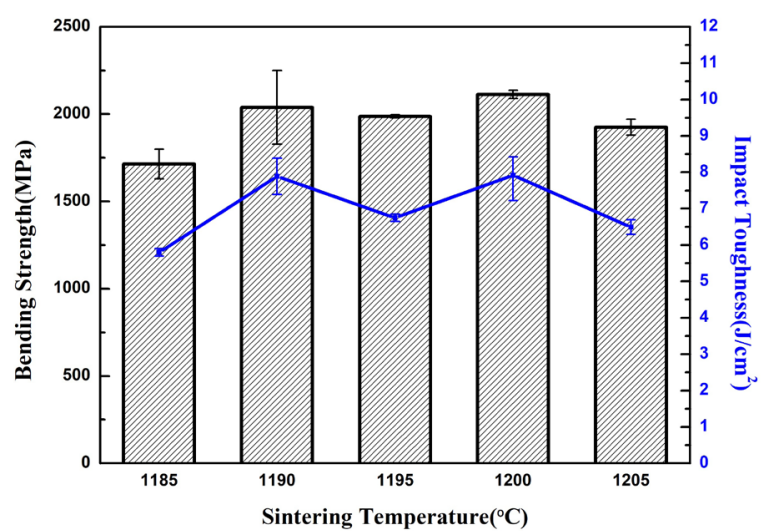

Fig. 9 Effect of sintering temperature on the impact toughness and bending strength of sintered HCCI 
rapidly increase initially and then fluctuate and finally decline as sintering temperature increases from $1185^{\circ} \mathrm{C}$ to $1205{ }^{\circ} \mathrm{C}$. Their maximums are reached at $1200{ }^{\circ} \mathrm{C}$, 2112.65MPa and $7.92 \mathrm{~J} / \mathrm{cm}^{2}$, respectively.

As sintering temperature increased, the alloy's density was gradually increased, so were its strength and toughness, because there were fewer and fewer pores in the matrix. When $15 \mathrm{Cr}$ sintered HCCI reached nearly full densification, further temperature rise caused microstructure to become coarse. Additionally, large rod-shaped carbide growth and carbide network formation will occur, which was favorable for crack propagation. Consequently, both strength and toughness decreased when the sintering temperature was over $1200^{\circ} \mathrm{C}$ as shown in Fig. 9 .

Based on the above discussion, the optimized sintering process could be determined as $1200{ }^{\circ} \mathrm{C}$ for 90 minutes at the vacuum of $5-10 \mathrm{~Pa}$.

\subsection{Wear resistance}

In order to evaluate the resistance of $15 \mathrm{Cr}$ sintered HCCI and compare it with sintered $20 \mathrm{Cr}$, the two alloys were firstly manufactured by optimized sintering process [25], and their main physical and mechanical properties are listed in Table 3.

The relationship between mass loss of $15 \mathrm{Cr}$ sintered HCCI and time under different impact condition during impact abrasive wear process is shown in Fig. 10. The result reveals that in the first $10 \mathrm{~min}$ of the test, mass loss is quite large because there is a running-in period between upper and down samples as shown in Fig. 2. In the subsequent wear process, its mass loss changed with time display periodic fluctuation. The higher the impact energy was, the larger the average mass loss per hour and the shorter the fluctuation period became. This wear mode may mean that micro-crack nucleation, propagation and junction with each other took place near the wear surface or subsurface of the sample, which finally caused chip off falling or mass loss fluctuation peak. In contrast, wear mass loss of $15 \mathrm{Cr}$ sintered HCCI was quite low and varied with time with very small fluctuation under impact

Table 3 Properties of Sintered HCCI

\begin{tabular}{lcccc}
\hline $\begin{array}{l}\text { HCCI } \\
\text { Code }\end{array}$ & $\begin{array}{c}\text { Density } \\
\left(\mathrm{g} / \mathrm{cm}^{3}\right)\end{array}$ & $\begin{array}{c}\text { Hardness } \\
(\mathrm{HRC})\end{array}$ & $\begin{array}{c}\text { Bending } \\
\text { strength } \\
(\mathrm{MPa})\end{array}$ & $\begin{array}{c}\text { Impact } \\
\text { toughness } \\
\left(\mathrm{J} / \mathrm{cm}^{2}\right)\end{array}$ \\
\hline $15 \mathrm{Cr}$ & 7.64 & 63.9 & 2112 & 7.9 \\
$20 \mathrm{Cr}$ & 7.44 & 58.0 & 2122 & 6.5 \\
\hline
\end{tabular}

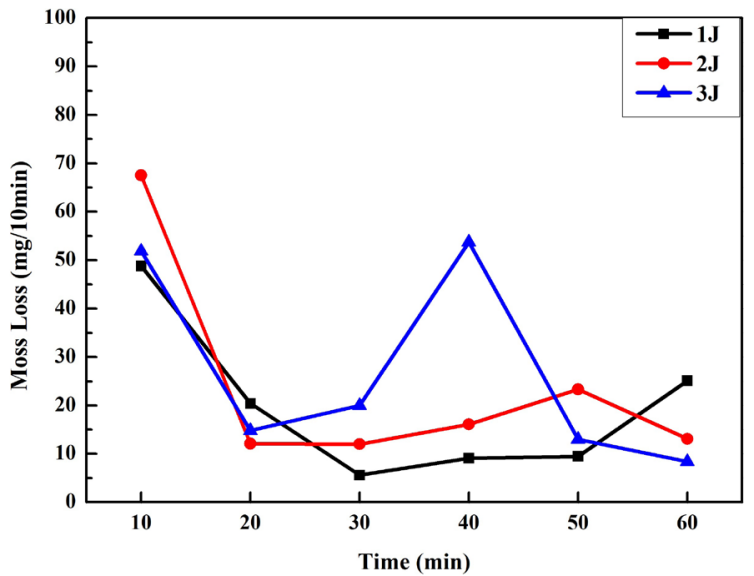

Fig. 10 The relationship between the mass loss and the time of the $15 \mathrm{Cr}$ sintered HCCI with the best mechanical properties under the impact abrasive wear test

energy of 1 and $2 \mathrm{~J} / \mathrm{cm}^{2}$; however, in the case of impact energy of $3 \mathrm{~J} / \mathrm{cm}^{2}$, its wear mass loss was magnified seriously. Therefore, $15 \mathrm{Cr}$ sintered HCCI is of good impact abrasive wear resistance when its impact energy is not higher than $2 \mathrm{~J} / \mathrm{cm}^{2}$.

The wear surface morphology of $15 \mathrm{Cr}$ sintered HCCI and the microstructure near the surface after impact abrasive wear under different impact energy are shown in Fig. 11. In the case of impact energy $1 \mathrm{~J} / \mathrm{cm}^{2}$, there are many obvious large and deep furrows on the wear surface as shown in Fig. 11 (a) and there are also a few microcracks in the area close to the wear surface on the upper side of Fig. 11 (c). Hence, micro-cutting would be main wear mechanism in such circumstance. As impact energy was $2 \mathrm{~J} / \mathrm{cm}^{2}$, the wear subsurface consisted of brittle fracture, fatigue spalling as well as some shallow furrows, and broken carbides and microcracks propagated along carbide boundaries or inside them could be found in a deep area nearby the wear surface, as shown in Fig. 11 (b) and (d). Therefore, brittle fracturing and fatigue spalling would become primary wear mechanism in this case.

\section{Conclusion}

1. The fully dense hypoeutectic sintered HCCI with $15 \mathrm{wt} \% \mathrm{Cr}$ was prepared by SLPS technique with water atomized prealloyed powders as initial materials.

2. The microstructure of $15 \mathrm{Cr}$ sintered HCCI consists of hexagonal $\mathrm{M}_{7} \mathrm{C}_{3}$-type carbide and martensite, and a small amount of austenite. The volume fraction of carbide is stable at about $40 \%$. Sintering temperature exerts a great influence on carbide's evolution. 

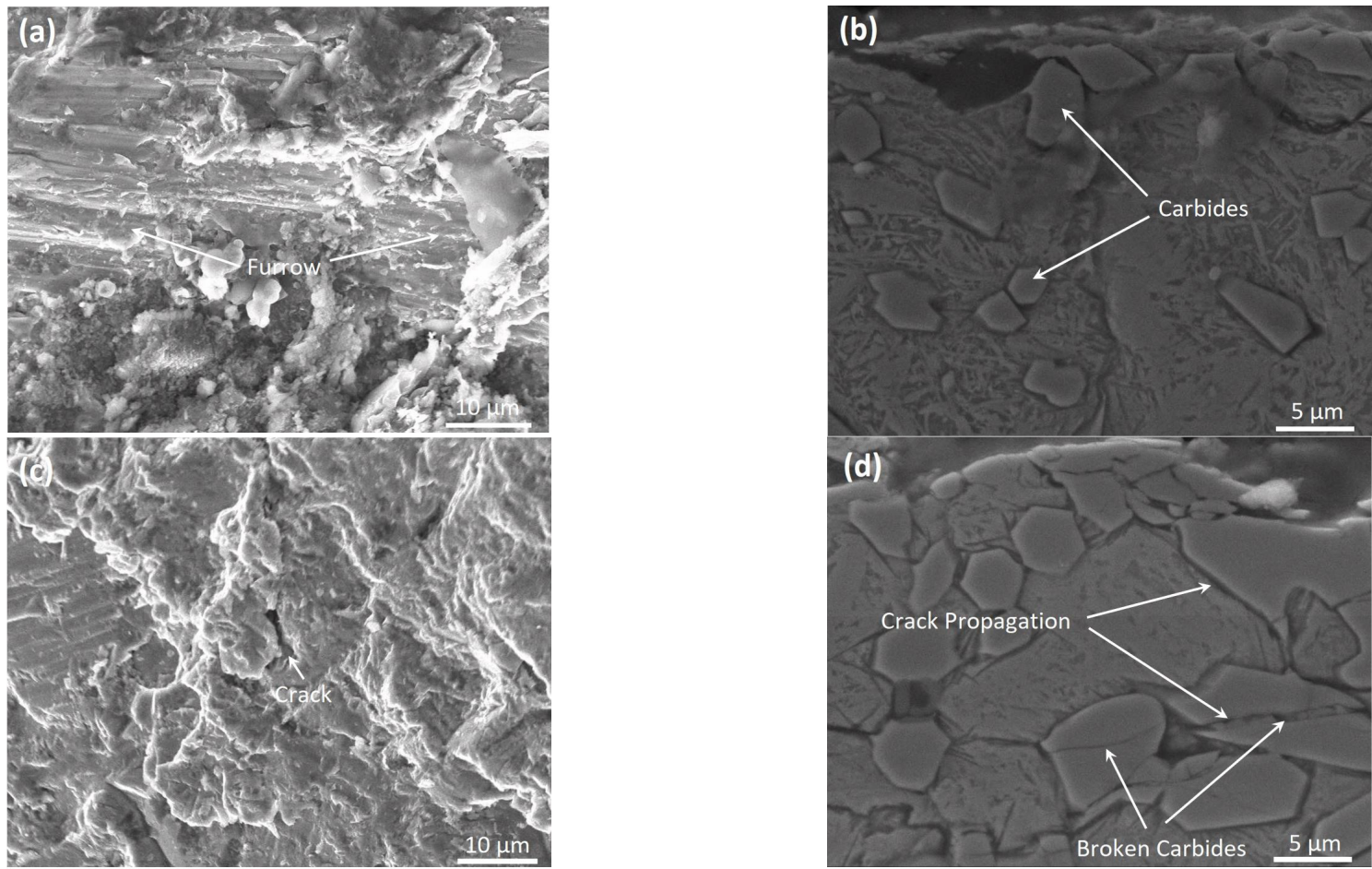

Fig. 11 Topography and subsurface morphology of $15 \mathrm{Cr}$ sintered HCCI under different impact energies: $1 \mathrm{~J} / \mathrm{cm}^{2}$ (a) and (c); $2 \mathrm{~J} / \mathrm{cm}^{2}$ (b) and (d)

The higher the temperature is, the larger rod-shape carbides and the more fully developed the carbide dendrites become.

3. The optimized sintering process of $15 \mathrm{Cr}$ sintered $\mathrm{HCCI}$ is of $1200{ }^{\circ} \mathrm{C}$ for $90 \mathrm{~min}$, and its mechanical properties has the hardness of $63.9 \mathrm{HRC}$, bending strength of $2112.65 \mathrm{MPa}$ and impact toughness of $7.92 \mathrm{~J} / \mathrm{cm}^{2}$. Both mechanical properties and impact abrasive wear resistance could be comparable to sintered HCCI with $20 \mathrm{wt} \% \mathrm{Cr}$.

4. Impact abrasive wear mechanism of $15 \mathrm{Cr}$ hypoeutectic sintered HCCI involves micro-cutting, brittle

\section{References}

[1] Tabrett, C. P., Sare, I. R., Ghomashchi, M. R. "Microstructureproperty relationships in high chromium white iron alloys", International Materials Reviews, 41(2), pp. 59-82, 1996. https://doi.org/10.1179/imr.1996.41.2.59

[2] Ben Zine, H. R., Balázsi, K., Balázsi, Cs. "The Effect of the Chemical Composition to the End-Properties of Ceramic Dispersed Strengthened 316L/Y2O3 Composites", Periodica Polytechnica Chemical Engineering, 63(3), pp. 370-377, 2019. https://doi.org/10.3311/PPch.13591

[3] Lv, Y., Sun, Y., Zhao, J., Yu, G., Shen, J., Hu, S. "Effect of tungsten on microstructure and properties of high chromium cast iron", Materials \& Design, 39, pp. 303-308, 2012.

https://doi.org/10.1016/j.matdes.2012.02.048 fracturing and fatigue spalling under different impact energies. Micro-cutting would be main wear mechanism in the case of impact energy $1 \mathrm{~J} / \mathrm{cm}^{2}$, and both brittle fracturing and fatigue spalling would become primary wear mechanism in the case of impact energy $2 \mathrm{~J} / \mathrm{cm}^{2}$.

\section{Acknowledgement}

This research work is supported by the National Nature Science Foundation of China No. 51574119.

[4] Bedolla-Jacuinde, A., Guerra, F. V., Mejía, I., Zuno-Silva, J., Rainforth, M. "Abrasive wear of V-Nb-Ti alloyed high-chromium white irons", Wear, 332-333, pp. 1006-1011, 2015. https://doi.org/10.1016/j.wear.2015.01.049

[5] Zhi, X., Xing, J., Fu, H., Xiao, B. "Effect of niobium on the as-cast microstructure of hypereutectic high chromium cast iron", Materials Letters, 62(6-7), pp. 857-860, 2008. https://doi.org/10.1016/j.matlet.2007.06.084

[6] Scandian, C., Boher, C., de Mello, J. D. B., Rezaï-Aria, F. "Effect of molybdenum and chromium contents in sliding wear of high-chromium white cast iron: The relationship between microstructure and wear", Wear, 267(1-4), pp. 401-408, 2009. https://doi.org/10.1016/j.wear.2008.12.095 
[7] Bedolla-Jacuinde, A. "Microstructure of vanadium-, niobium- and titanium-alloyed high-chromium white cast irons", International Journal of Cast Metals Research, 13(6), pp. 343-361, 2001. https://doi.org/10.1080/13640461.2001.11819416

[8] Çetinkaya, C. "An investigation of the wear behaviours of white cast irons under different compositions", Materials \& Design, 27(6), pp. 437-445, 2006.

https://doi.org/10.1016/j.matdes.2004.11.021

[9] Imurai, S., Thanachayanont, C., Pearce, J. T. H., Tsuda, K., Chairuangsri, T. "Effects of Mo on microstructure of as-cast 28 wt.\% Cr-2.6 wt.\% C-(0-10) wt.\% Mo irons", Materials Characterization, 90, pp. 99-112, 2014.

https://doi.org/10.1016/j.matchar.2014.01.014

[10] Tian, Y., Ju, J., Fu, H., Ma, S., Lin, J., Lei, Y. "Effect of Chromium Content on Microstructure, Hardness, and Wear Resistance of As-Cast Fe-Cr-B Alloy", Journal of Materials Engineering and Performance, 28(10), pp. 6428-6437, 2019.

https://doi.org/10.1007/s11665-019-04369-5

[11] Ibrahim, M. M., El-Hadad, S., Mourad, M. "Enhancement of wear resistance and impact toughness of as cast hypoeutectic high chromium cast iron using niobium", International Journal of Cast Metals Research, 31(2), pp. 72-79, 2018.

https://doi.org/10.1080/13640461.2017.1366144

[12] Chong, X. Y., Hu, M. Y., Wu, P., Shan, Q., Jiang, Y. H., Li, Z. L., Feng, J. "Tailoring the anisotropic mechanical properties of hexagonal $\mathrm{M}_{7} \mathrm{X}_{3}(\mathrm{M}=\mathrm{Fe}, \mathrm{Cr}, \mathrm{W}, \mathrm{Mo} ; \mathrm{X}=\mathrm{C}, \mathrm{B})$ by multialloying", Acta Materialia, 169, pp. 193-208, 2019.

https://doi.org/10.1016/j.actamat.2019.03.015

[13] Yin, Y., Pan, C., Zhang, R., Zhao, C., Qu, Y. "The effect of Ti addition on the microstructure and properties of high chromium iron-based coatings", Journal of Alloys and Compounds, 765, pp. 782-790, 2018.

https://doi.org/10.1016/j.jallcom.2018.05.230

[14] Hou, Y., Wang, Y., Pan, Z., Yu, L. "Influence of rare earth nanoparticles and inoculants on performance and microstructure of high chromium cast iron", Journal of Rare Earths, 30(3), pp. 283-288, 2012. https://doi.org/10.1016/s1002-0721(12)60038-6

[15] Peev, K., Radulovic, M., Fiset, M. "Modification of Fe-Cr-C alloys using mischmetal", Journal of Materials Science Letters, 13(2), pp. 112-114, 1994.

https://doi.org/10.1007/bf00416817

[16] Albertin, E., Beneduce, F., Matsumoto, M., Teixeira, I. "Optimizing heat treatment and wear resistance of high chromium cast irons using computational thermodynamics", Wear, 271(9-10), pp. 1813-1818, 2011. https://doi.org/10.1016/j.wear.2011.01.079

[17] Jena, P. S. M., Rai, R. K., Sahu, J. K. "Improvement of toughness of high chromium white cast iron: duplex ferritic-austenitic matrix", Materials Science and Technology, 34(3), pp. 299-304, 2018. https://doi.org/10.1080/02670836.2017.1385993
[18] Mandal, S. S., Ghosh, K. S., Mondal, D. K. "Microstructure, hardness, toughness and abrasive wear resistance of 16.0 wt. \% chromium white iron after continuous and cyclic destabilisation treatment", International Journal of Cast Metals Research, 31(3), pp. 177-192, 2018. https://doi.org/10.1080/13640461.2017.1408182

[19] Lai, J. P., Pan, Q. L., Wang, Z. B., Cui, H. R., Wang, X. D., Gao, Z. Z. "Effects of Destabilization Temperature on the Microstructure and Mechanical Properties of High Chromium Cast Iron" Journal of Materials Engineering and Performance, 26(10), pp. 4667-4675, 2017. https://doi.org/10.1007/s11665-017-2943-9

[20] Mandal, S. S., Ghosh, K. S., Mondal, D. K. "Microstructure, Mechanical and Abrasive Wear Behavior of 8.0 wt pct Cr White Iron Subjected to Continuous and Cyclic Annealing Treatment", Metallurgical and Materials Transactions A: Physical Metallurgy and Materials Science, 48(7), pp. 3432-3444, 2017. https://doi.org/10.1007/s11661-017-4101-2

[21] Gelfi, M., Pola, A., Girelli, L., Zacco, A., Masotti, M., La Vecchia, G. M. "Effect of heat treatment on microstructure and erosion resistance of white cast irons for slurry pumping applications", Wear, 428-429, pp. 438-448, 2019. https://doi.org/10.1016/j.wear.2019.03.011

[22] Gu, J., Xiao, P., Song, J., Li, Z., Lu, R. "Sintering of a hypoeutectic high chromium cast iron as well as its microstructure and properties", Journal of Alloys and Compounds, 740, pp. 485-491, 2018. https://doi.org/10.1016/j.jallcom.2017.11.189

[23] Röttger, A., Weber, S., Theisen, W. "Supersolidus liquid-phase sintering of ultrahigh-boron high-carbon steels for wear-protection applications", Materials Science and Engineering A: Structural Materials Properties Microstructure and Processing, 532, pp. 511-521, 2012. https://doi.org/10.1016/j.msea.2011.10.118

[24] Liu, J., Lal, A., German, R. M. "Densification and shape retention in supersolidus liquid phase sintering", Acta Materialia, 47(18), pp. 4615-4626,1999. https://doi.org/10.1016/s1359-6454(99)00320-1

[25] Xiao, P. Song, J., Chen, C., Liu, Y., Li, Z., Gu, J. "烧结亚共晶 高铬铸铁制备及其显微组织与性能" (Sintering Fabrication of a Hypoeutectic High Chromium Cast Iron as well as Its Microstructure and Properties), Journal of Hunan University (Natural Sciences), 44(6), pp. 37-44, 2017. (in Chinese) https://doi.org/10.16339/j.cnki.hdxbzkb.2017.06.007 